\title{
Integrated Power Market in West Africa: An Overview
}

\author{
Adeniyi Adebayo ${ }^{1}$, Samuel Adeniji ${ }^{2}$ \\ ${ }^{1}$ Institute for Energy Studies, National Research University Higher School of Economics, Moscow, Russia \\ ${ }^{2}$ Peter A. Allard School of Law, University of British Columbia, Vancouver, Canada
}

Email address:

aadebayo@hse.ru (A. Adebayo)

\section{To cite this article:}

Adeniyi Adebayo, Samuel Adeniji. Integrated Power Market in West Africa: An Overview. Journal of Public Policy and Administration. Vol. 2, No. 3, 2018, pp. 20-27. doi: 10.11648/j.jppa.20180203.11

Received: October 8, 2018; Accepted: October 25, 2018; Published: November 16, 2018

\begin{abstract}
Lack of access to affordable electricity is a major detriment to the development of the resource-rich West African region. Accelerating development in this region will require massive expansion of access to electricity. The purpose of this paper is to more clearly identify the status of current efforts to improve the energy situation. Analysis of existing literature shows that an increasingly interesting aspect of solving power problems in the developing word is the design and implementation of competitive electricity markets. In West Africa, the most ambitious plan to reform the Power Sector is the West African Power Pool (WAPP). By conducting a review of current power sector integration projects and approaches to market liberalization in West Africa, this paper provides a robust basis for future research on paths for energy security in the region.
\end{abstract}

Keywords: Energy Security, Regional Trade, West African Power Pool

\section{Introduction}

\subsection{West African Integration}

West Africa is an important sub-region of the African continent, representing a third of the continent's total population and economic activity by gross domestic product. Integration of regional economies has been a strong trend in recent times with success stories like the European Union and the North America Free Trade Agreement. The West African countries have attempted to replicate some of these global best practices by forming common unions and creating plans to harmonize the countries' economies. The most evident of the attempts is the Economic Community of West African States (ECOWAS), a regional bloc integrating the economic and political interests of West African nations.

ECOWAS unites 15 West African countries. The size of the ECOWAS region is roughly double that of the European Union $\left(3,892,685 \mathrm{~km}^{2}, 25\right.$-member states). The organization plays an important role in African economic integration through membership in the African economic community.

The New Partnership for Africa's Development, has set ambitious integration goals for Africa in various sectors, including energy. Its Short-Term Action Plan for Infrastructure promotes integration initiatives in the energy sector, notably through the West Africa Power Pool (WAPP) and other power pools (Southern Africa Power Pool, Central African Power Pool). These projects, with the support of major international finance institutions (such as the World Bank) and international donors (such as the United States Agency for International Development or the European Union through its EU Africa Partnership on Infrastructure) aim at integrating the different power systems in the region and improving access to reliable, affordable and sustainable energy.

Results of modeling different power pools in Africa reveal the viability of such projects[3]. This paper will provide an overview of the West African Power Pool (WAPP) initiative and important issues potentially limiting its success.

\subsection{Electricity in West Africa}

In order to understand the underlying problem of electricity in West Africa, it is important to consider data on electricity access and generation. According to the international energy agency, Sub-Saharan Africa has more people living without access to electricity than any other world region - more than 620 million people, representing about half of the global population without access to electricity (Figure 1) [4]. Most of the people who lack access 
to electricity reside in rural areas where demand is low and sparsely located. This fact means electrification projects in these areas are usually not financially viable. The figure below illustrates the situation with access to electricity in Africa. Nigeria, Africa's most populous nation contributes roughly $15 \%$ of Africans without access to electricity.

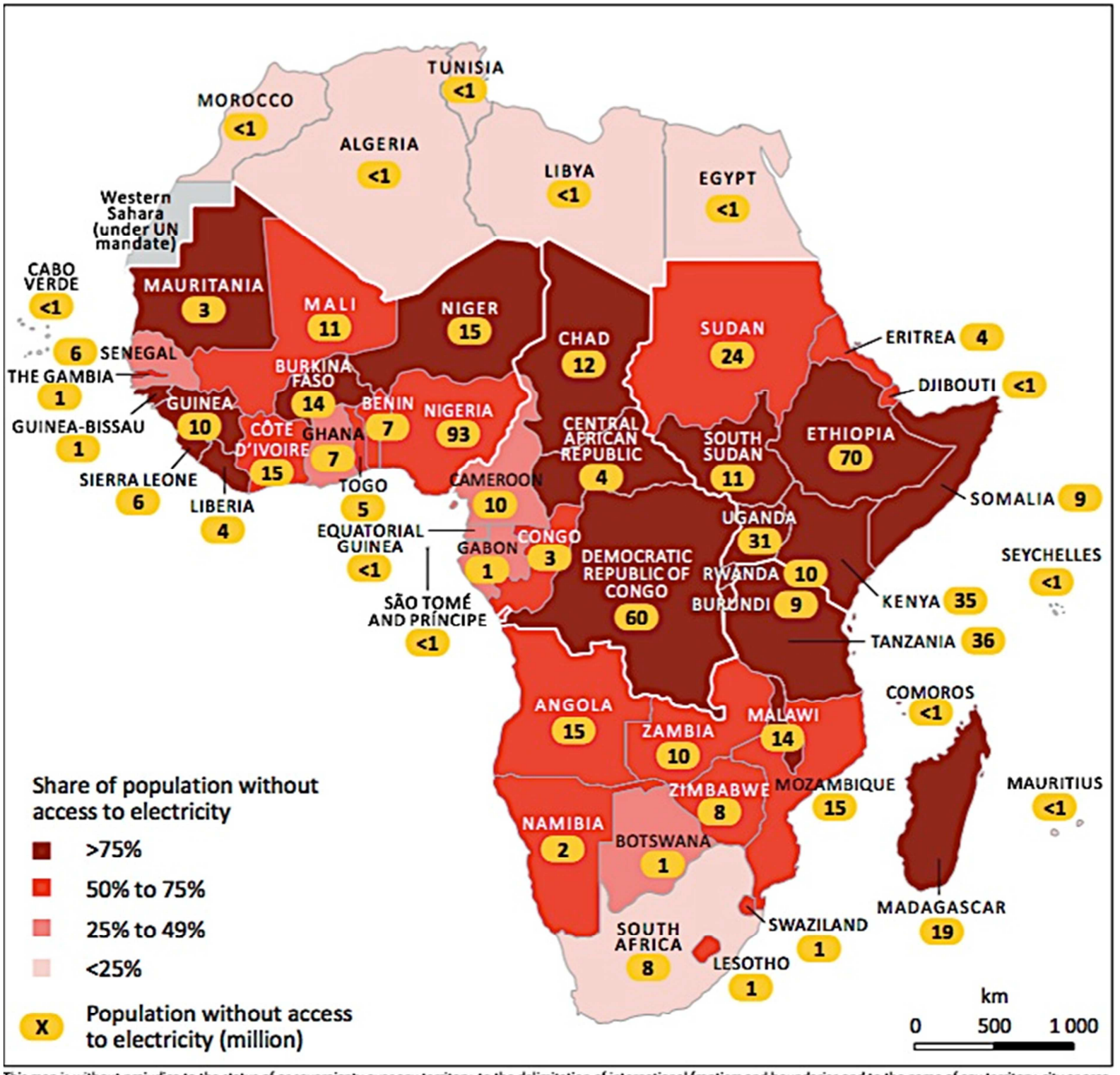

Figure 1. Number and share of people without access to electricity, (iea. org).

Generation, even though an important problem is not the only problem facing electricity companies in the West African region, the EIA estimates that distribution losses across the region is about $20 \%$ of generation [1]. This is largely due to aging infrastructure and the lack of maintenance of existing infrastructure. Beyond this, local technical know-how has also been a major contributor to the poor safety and maintenance profile of infrastructure in the region. It is worth noting that modeling of power systems in the region, as well as technical appraisals of big projects have typically been done in Europe or the United States. While this is in itself is not a problem but rather underscores the lack of local knowledge hubs in the power sector to support policy decisions and implementation.
The region's potential is currently being squandered due to poor investment decisions, lack of innovation in supplying customers, and poor coordination and integration among the West African nations. Availability of energy resources has not translated to increased electricity generation nor greater electrification of the region. Take the case of Nigeria as an example, with its vast energy resource base, it still struggles to provide electricity for more than half of her people.

The West African countries have at different points attempted to reform their individual power systems. However, most of the attempts have not been successful and have received little scholarly analysis. The failed privatization of Senegal's power system is discussed by the World Bank [5]. The Nigeria reform process and situation is 
presented in Ikeme and Ebohon [6]. The 2001 privatization of the Cameroonian power company was extensively analyzed by Pineau [7]. An important conclusion from these sources is the lack of policy coherence on the reform strategies undertaken by these countries. Further, the dearth of data on most of the privatization processes makes it difficult for a proper scrutiny of current ongoing processes. However, as democracy takes more ground across the region, it is expected that future attempts will be more transparent and open to public and academic scrutiny.

The power systems of most West African countries remain vertically integrated under state control. This is so, even though there has been an active promotion of privatization and liberalization reforms by international financial agencies such as the World Bank. In fact, as shown in Table 1, only two ECOWAS countries (Cape Verde and Cote d'Ivoire) have a power sector owned in majority by (foreign) private companies. In Mali, for instance, re-nationalization occurred in 2005, years after privatization. This happened because of political and investment problems, with shares of the private owner sold to the State of Mali and to Industrial Promotion Services (West Africa), a subsidiary of the Aga Khan Fund for Economic Development. Scenarios like these make it even more difficult to woo investors to participate in the electricity sector of West African countries.

In terms of national sector integration, all countries remain vertically integrated, except for four countries with independent distribution companies: Benin, Ghana and Togo and more recently Nigeria. Only five out of the 15 ECOWAS countries have independent power producers (IPPs): Burkina Faso, Cote d'Ivoire, Ghana, Nigeria and Senegal [8].

It is easy to conclude that privatization and liberalization reforms have not been largely embraced in ECOWAS countries. This has led to non-competitive companies with poorly managed assets delivering poor service to their customers.

Table 1. Economic and electricity sector information (World Bank, EIA).

\begin{tabular}{|c|c|c|c|c|c|}
\hline Country & Population & $\begin{array}{l}\text { GNI per capita, } \\
\text { (US\$) }\end{array}$ & $\begin{array}{l}\text { Capacity } \\
\text { (MW) }\end{array}$ & $\begin{array}{l}\text { Owner (Generation, Transmission and } \\
\text { Distribution) }\end{array}$ & $\begin{array}{l}\text { Year of privatization and \% } \\
\text { of private ownership }\end{array}$ \\
\hline Benin & $9,983,884$ & 810 & 122 & State & \\
\hline Burkina Faso & $18,450,494$ & 710 & 177 & State & \\
\hline Cape Verde & 524,833 & 1870 & 7 & Electricidade de Portugal; Agus de Portugal & $2000(51 \%)$ \\
\hline Cote d'Ivoire & $22,671,331$ & 1550 & 909 & Bouygues group & $(51 \%)$ \\
\hline Gambia & $1,882,450$ & 450 & 29 & State & \\
\hline Ghana & $27,043,093$ & 1620 & 1432 & State & \\
\hline Guinea & $10,628,972$ & 480 & 284 & State & \\
\hline Guinea-Bissau & $1,844,000$ & 570 & 21 & State & \\
\hline Liberia & $4,503,000$ & 400 & 253 & State & \\
\hline Mali & $17,600,000$ & 720 & 280 & State & 2000 , re-nationalized in 2005 \\
\hline Niger & $19,899,000$ & 430 & 105 & State & \\
\hline Nigeria & $182,202,000$ & 2950 & 5898 & Successor Companies, Independent Power Plants & In progress \\
\hline Senegal & $13,508,715$ & 1050 & 239 & State & \\
\hline Sierra Leone & $6,453,000$ & 720 & 132 & State & \\
\hline Togo & $7,305,000$ & 580 & 28 & State & \\
\hline
\end{tabular}

\section{The West African Power Pool Initiative}

\subsection{Power Pools}

Power pools are formal groups of power utilities that exchange electricity in order to reduce production costs. The fundamental goal of power pools is to allocate output among a group of generating units in a manner which minimizes costs while meeting a given set of constraints.

Table 2 below summarizes the four main types of power pools [9]. The distinguishing characteristic is the level of integration for a given set of constraints. For a looselyintegrated system, interconnection between the different power systems simply guarantees synchronization, without any particular coordination or joint optimization of individual systems. Trade is made under long-term power exchange agreements, while additional energy sales only happen in emergency cases. An example of an interconnected power system with low-level integration is the Central Asian Power System connecting Uzbekistan, Kazakhstan, Tajikistan and
Kyrgyzstan. In such an arrangement, cost savings are mostly the result of economies of scale in power generation: large projects can sell their output to more consumers, and therefore be more easily viable. Prices are set through negotiations between regulatory authorities or through bilateral or multilateral agreements.

Loose pools are more integrated by coordinating dispatch between power systems and allowing for more short-term exchanges between the various power systems. In a loose pool, reserve capacity can be shared, resulting in additional savings.

In "tight" pools, all power plants are dispatched from a centralized location, according to least production cost principles and under a certain set of transmission capacity constraints. This dispatching approach can minimize shortrun generation costs and therefore be a source of additional cost savings for production.

In competitive pool arrangements, a spot market replaces all formal and explicit optimization techniques. Competitive markets are responsible for the dispatch of electricity, which is expected to be optimal in the absence of market failures. Competitive pool arrangements can be found across the 
world, mostly in developed regions like the EU and North America. Typically, electricity pooling is a reluctant activity for nations. A clear confirmation of this is the fact that for 2014, global electricity exports were $3 \%$ of production, in contrast to about $50 \%$ for oil [1]. However, when nations pool resources to achieve wide-area trade, savings can be made while achieving lower prices for consumers. An example is the New England Power Pool (NEPOOL), which is estimated to have saved over $\$ 30$ million dollars from exchanging energy alone in 1978 [10].

Recognizing the role a common market can play in alleviating some of the power problems, ECOWAS agreed on developing a regional power pool. However, as would be seen in the next sections, the current format of the West African Power Pool does not represent any of the power pools represented below and hence has been ineffective.

Table 2. Types of power pools.

\begin{tabular}{llll}
\hline & Interconnected grid & Loose pool & Tight pool \\
\hline System operations & Synchronized utilities & Dispatch coordination & Centralized dispatch \\
Trade & Bulk power contracts between & Power purchase agreements. & Power purchase agreements \\
utilities. Emergency support & Forward contracts. Spot market. \\
Cost savings & Economies of scale & Reserve sharing & Least-cost planning \\
Price mechanism & Tariffs by regulators or agreements & $\begin{array}{l}\text { Tariffs by regulators or } \\
\text { agreements }\end{array}$ & Price set by regulators \\
\hline
\end{tabular}

\subsection{The West African Power Pool (WAPP)}

The West African Power Pool was created by the decision of the ECOWAS Heads of State with the aim of curtailing the power deficit prevalent in the region and creating a competitive regional electricity market. Even though, WAPP was formed in 1999, its activities only started in 2006 after the ECOWAS summit adopted articles regulating its functions. The WAPP functions as a specialized institution of ECOWAS with headquarters in Benin. In pursuing its mandate, WAPP has set the following objectives [11]:

i Formalizing an official and extended collaboration in the region for the development of power generation and transmission with a view to enhancing power security in the region;

ii Improving power system reliability and power supply;

iii Minimizing power network operating costs;

iv Establishing a legal and regulatory framework applicable across the region.

$\mathrm{v}$ Creating a transparent and reliable mechanism for trade-dispute resolution.

Energy trading in West Africa began in 1972 with the commissioning of a transmission line from Ghana to Togo and Benin to export excess power from Ghana [12]. The WAPP includes both public and private generation, transmission, and distribution companies from 14-member countries. Unlike countries in southern Africa where South Africa boasts excess generation and robust interconnections with its neighbors, there were limited interconnections between member countries when the WAPP was established and no country had spare capacity to share. However, the region has moved quickly to develop governing protocols and needed infrastructure, possibly benefiting from higher levels of integration and influence that ECOWAS has compared with regional institutions in other parts of Africa. A revised Master Plan for generation and transmission expansion was released in 2011 and market and operating rules for the WAPP Regional Electricity Market have been established. There is a roadmap consisting of three phases to transition from the sole use of bilateral agreements to a competitive regional market. ECOWAS has taken a proactive approach to ensure priority infrastructure projects are completed using Special Purpose Companies under a publicprivate partnership (PPP) framework to design, finance and own these projects.

The master plan for the development of the WAPP, was finalized by an American consulting company, Nexant, and presented to the funding agency of the project, USAID, and to the ECOWAS Secretariat. This master plan is based on a technical study of the power sector of WAPP countries, performed by a 10-person Project team, assisted by a threeperson "West Africa Counterpart Technical team" (from Ghana, Burkina Faso and Senegal) [3]. Following this master plan, 14 priority interconnections have been identified. Fig. 2 below illustrates the existing and proposed interconnections. The Master Plan consists of three phases to transition from just bilateral power exchanges to a fully competitive electricity market. The WAPP is currently in Phase 1 of the Road Map. In this phase, market participants consist of one representative from each country. Independent Power Producers (IPPs) with a regional project are considered a special case and can also participate as members. During Phase 1, all transactions are based on bilateral contracts using standard contract forms approved by the ECOWAS regional electricity regulatory authority (ERERA). Access to transmission capacity is allocated on a "first come, first served" basis. Wheeling (transmission outside grid boundaries) is permitted in long and medium-term contracts, but short-term contracts are limited to adjacent countries. Based on available literature, there is no confirmation on the approval of the mechanisms devised by the WAPP including on application procedures and standard contracts for IPPs.

The second phase of WAPP development is expected to expand market participation to more private companies and the development of a day-ahead market. From the WAPP documents analyzed, there are no timelines indicated for when and how this will be implemented. Phase 3 is described as being in the "very long term" and specific goals and guidelines for market operations are not yet defined. This vague roadmap raises important questions for 
implementation.

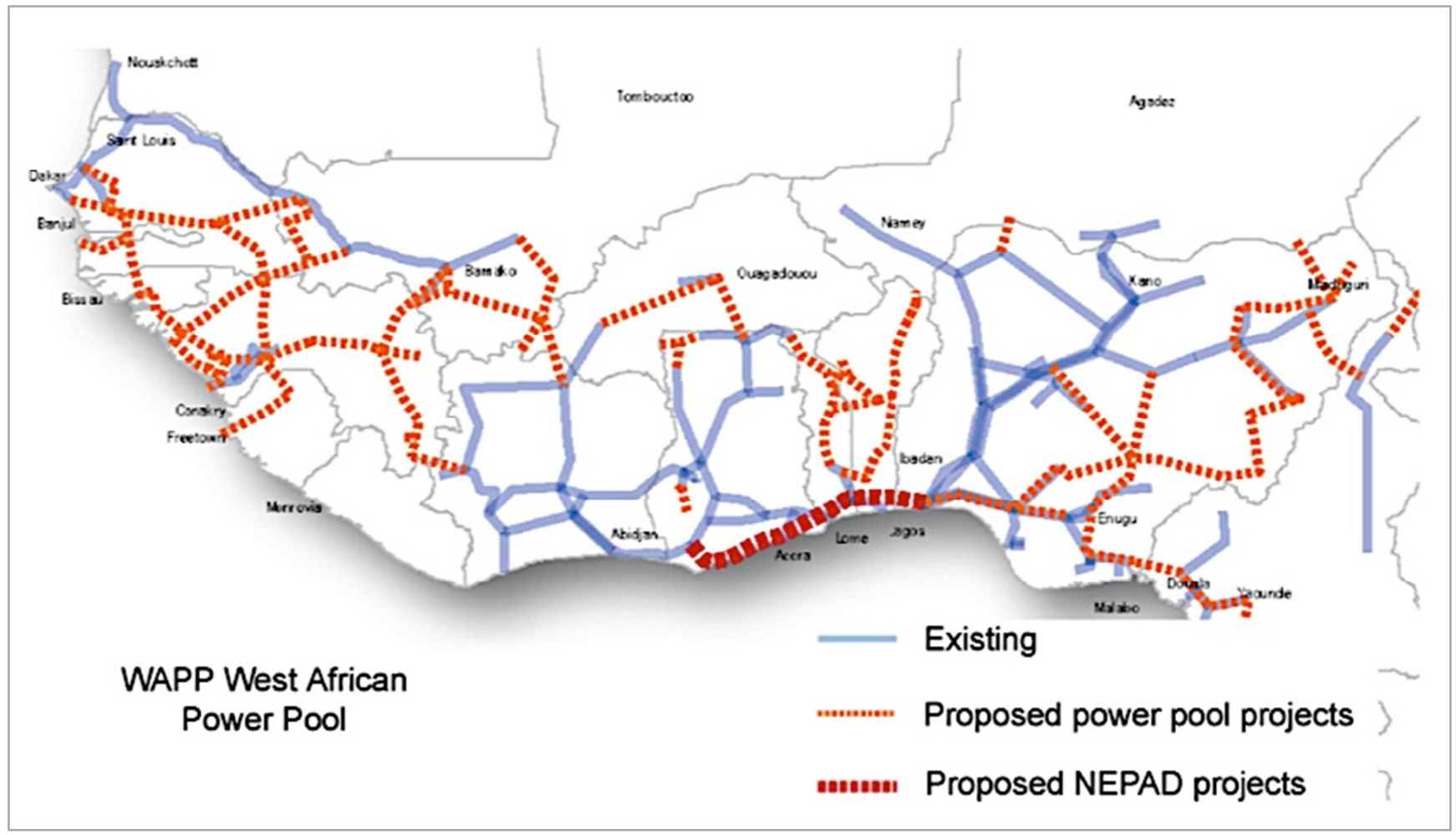

Figure 2. WAPP interconnections [14].

A report of the World Energy Council identifies four major benefits of a regionally integrated energy sector including improved security of supply, better economic efficiency, enhanced environmental quality and facilitation of renewable energy projects [15].

In order for a power pool like WAPP to be successful, more market reforms are needed in the individual countries. As shown in Table 1 above, it can be induced that most West African countries are wary of opening up their power markets and unbundling their utilities. This can mostly be attributed to a lack of collective political will, poor institutional capacity and failures of prior reform attempts (like in the case of Mali). The graph below illustrates the low volume of energy trade between the WAPP countries. It is also important to note most of current generation comes from thermal stations, $60 \%$ of the region's $9.8 \mathrm{GW}$ capacity is currently generated by thermal power stations [1].. Plans for incorporating renewable energy sources are being touted but no concrete regional plans have been made in this direction.

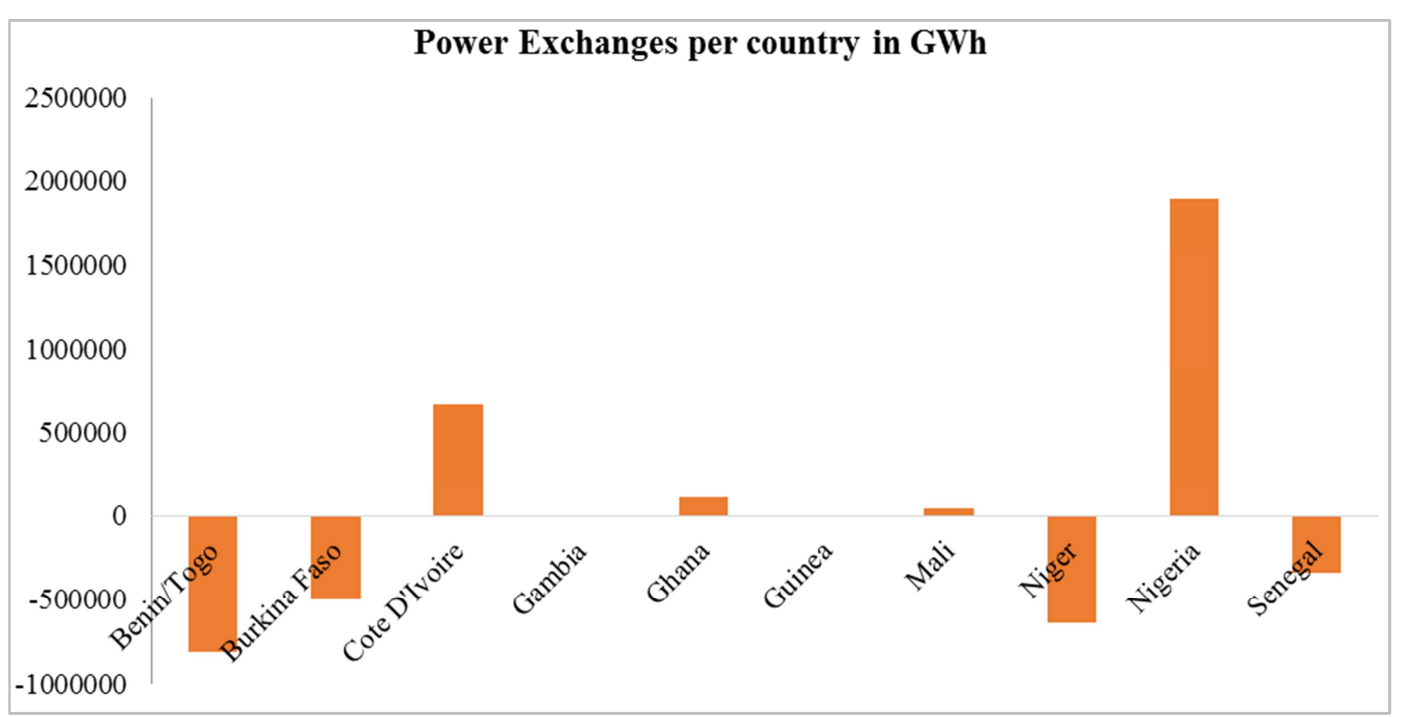

Figure 3. Energy Exchanges per country in GWh [11] (Negative values indicate imports while positive values indicate exports). 
One reason for this low volume of energy trade as rightly identified by Oseni, M. O. and Pollitt, M. G as the lack of adequate transmission capacity between the countries [16]. It is obvious that the development of WAPP beyond bilateral power exchanges will require significant 'cross border' investment in transmission capacity. The capacity of current cross-border transmission has meant that at best bilateral power swaps are the only feasible form of electricity trade available to the countries. The table below on the existing transmission infrastructure helps sums up this point of view.

Table 3. Existing Transmission Infrastructure Summary [12], [17].

\begin{tabular}{lll}
\hline Country 1 & Country 2 & Line Capacity (MW) \\
\hline Ghana & Cote d'Ivoire & 327 \\
Ghana & Togo/Benin & 310 \\
Senegal & Mali & 100 \\
Cote d'Ivoire & Burkina Faso & 327 \\
Nigeria & Togo/Benin & 686 \\
Nigeria & Niger & 169 \\
\hline
\end{tabular}

\subsection{Integration Projects}

Lack of transmission capacity remains one of the major banes of the West African Power Pool. The WAPP recognizes this and has invested resources in the integration and harmonization of the regional power systems.

Based on an updated Master Plan, the WAPP identified 5 priority sub-programs for generation and transmission projects listed below:

(1) Coastal Transmission Backbone (CTB) Sub-program to establish a robust link between national power systems in Zone A coastal countries (Ivory Coast, Ghana, Benin/Togo, Nigeria).

Status: Recognizing that this interconnection was critical for regional pooling, WAPP passed Resolution WAPP/26/Res.26/10/11 in 2011 to implement the project. Currently, 2 of the 4 sections of this transmission project have been completed. Funding is provided from a variety of sources including EUAfrica, the World Bank, European Investment Bank, Kuwaiti Fund, African Development Bank, KfW (German development bank), West African Development Bank (BOAD), ECOWAS Bank for Investment and Development (EBID).

(2) Inter-zonal Transmission Hub Sub-program to establish a stronger connection between states with large hydroelectric and gas-fired generation plants and landlocked countries currently relying heavily on dieselbased sources.

Status: 1 of the 5 sections of this transmission connection is completed. Funding has been provided by the World Bank, African Development Bank, EIB, Danida and Danish Mixed Credit, Government of Burkina Faso, Nordic Fund, NEPAD, USAID.

(3) North-core Transmission Sub-program to upgrade and extend existing interconnection capacity from areas with large hydroelectric plants on the Niger River Basin and gas-fired generation plants from Nigeria to
Niger, Burkina Faso and Benin.

Status: No project status was available from the WAPP.

(4) OMVG/OMVS Power System Development Subprogram to interconnect national power systems of Zone B countries and secure access to sources of hydroelectricity from facilities to be built on the Senegal River Basin (Guinea, Mali) and the Kondoure River Basin (Guinea).

Status: No project status was available from the WAPP.

(5) Ivory Coast, Liberia, Sierra Leone, Guinea Interconnection Project (CLSG) consisting of one hydropower facility and several interconnection lines to connect Zone A and Zone B countries.

Status: The transmission lines have received funding from EU-Africa. The $118 \mathrm{MW}$ hydropower plant, still at the pre-investment stage.

\section{Challenges to Integration}

In terms of the objectives sought by integration, as shown by WAPP documents, sector- specific objectives dominate with sub-themes such as "economy of scale and efficiency", "security of supply" and "reliability" being mentioned the most often. Improving transmission and trade and creating regional institutions are also high on the list of objectives. However, these lofty goals face certain challenges: both technical and socio-economic. Pineau posits in his concise analysis of the WAPP that a lack of clarity on what kind of power pool the WAPP should be clearly impedes its mission [17]. This is indicated in the lack of institutional framework of its activities across the three phases of development. There is little to point to how the WAPP intends to harmonize the very different levels of institutional regulation across the region to ensure a level-playing ground for everyone.

Interconnections between the WAPP countries remain weak and insufficient for serious cross-border trading. Even though there has been considerable commitment to improving these interconnections, the current pace of project implementation hampers the potentials of a region-wide competitive market in the near future. This reality further underscores the many dimensions of power sector reforms that must take place in the individual WAPP countries to increase the chances of success. These reforms have to confront the underdevelopment of not only the transmission capacity but also financial tools to fund interconnection projects in the face of weak legal and macroeconomic systems.

The WAPP has traditionally sourced funding for its projects through the World Bank and USAID. Some of these projects include the construction of a thermal generating unit of $14 \mathrm{MW}$ (US\$17.10million) and demand-side management (US\$3.38 million) jointly financed by the French Agency for Development, Nordic Development Fund and the Danish International Development Assistance [18]. With most of the funding coming from donor agencies and western development organizations, there is considerable uncertainty 
on the sustainability of the WAPP projects considering the volatility of the global financial market.

The small size of generating capacity across the region also poses a big challenge to the success of the WAPP. All the WAPP countries excluding Ghana, Nigeria and Cote d'Ivoire have power markets of under 1000MW. At such scales and with the vertically-integrated structure of most of the power sectors, it is tough to develop a competitive market with viable participants. The envisaged economies of scale expected by the WAPP can only work under a considerably larger market. Developing these markets will have to go hand-in-hand with industrialization and economic growth of the region. Most countries in the region have weak fiscal and economic policies making business competitiveness very poor. Without a considerable surge in demand, the long-term feasibility of the WAPP remains uncertain.

Another key challenge to power pools in developing countries raised by Bacon [19] is the negative effect of persistent large supply shortages on the competitiveness of the market. In developing a competitive market, adequate supply capacity is required to meet all the load segments (base, peak, and shoulder) on the power system. The WAPP countries experience supply shortages domestically, suggesting that power exchanges will also be plagued by these shortages limiting energy trade to long-term bilateral agreements between individual countries.

Project development by national utilities is important to the success of WAPP. Various financial reviews of national utilities reveal that these institutions lack the investment capacity to fund large power projects needed for regional development. Most of the utilities are in debt and their financing capability is low. In fact, most of these utilities run at a huge cost to the budgets of the WAPP countries. On the other hand, low tariffs and poorly-developed local financial systems serve as a barrier to participation from private companies. For there to be any significant chance of success for the WAPP, the countries have to undertake unpopular policy changes to revamp national utilities either through unbundling the sector and allowing more private sector participation or by cutting subsidies which have historically ensured low prices but put financial strain on the national utility companies.

\section{Conclusion}

West Africa, like most of Sub-Saharan Africa, faces the challenge of improving energy access to its population. Solving this problem is one of the most practical ways of improving the welfare and economic prospects of poor households. It has been recognised that regional collaboration in the energy sector holds prospects for enhancing electricity access and boosting regional trade. As described in this paper, the West African Power Pool (WAPP) aims to achieve this.

The problem of promoting wide-area trade within individual countries is well-studied as advanced nations have power sectors that have developed along these lines. On the other hand, multi-country electricity markets are more difficult to implement with few success stories like the Nord Pool in the European Union. Clearly, lack of physical interconnections which usually require huge investments is one of the main constraints. Harmonizing regulatory issues is another important aspect. Furthermore, countries have to cede some control over their internal markets to form strong region-wide regulatory and fiscal organizations to promote such energy trade. A flip side of this though is the enormous opportunity that exists in expanding electricity markets beyond national borders, especially in developing countries.

Considering the difficulties in setting up functioning competitive cross-border electricity markets, it is commendable that the West African Power Pool has set ambitious goals towards improving security of supply for its members through a competitive market. The initial development phase focused on improving interconnections should help strengthen the potentials for a competitive pool as more generation are developed in the individual countries. Despite the considerable progress made by the WAPP, conflicting goals between regional integration and national energy security and weak institutional capacity pose great challenges to the implementation of plans.

A key gap identified in the analyzed literature pertains to the prospects of renewable energy generation in the West African Power Pool. The WAPP roadmap is quite very vague on the incorporation of renewables. On the other hand, the WAPP has invested in building gas pipelines from Nigeria across the region to boost supply to thermal power stations. It is unclear from literature what an increased renewable portfolio will mean for the pool, especially when the pool develops into a spot market.

Another key missing link in the examined literature is dealing with dispersed demand that characterizes the region. The biggest demands for electricity seem to be in the urban centers with some countries (Nigeria and Ghana) disproportionately accounting for most of the electricity demand in the region. This scenario poses challenges to market design. Without sustained increases in electricity consumption backed by economic growth, it seems attracting foreign investment for the huge infrastructure projects needed by the WAPP will be a great challenge.

\section{References}

[1] U. S. Energy Information Administration, "International Energy Statistics," Independant statistics and analysis, U. S. Energy Information Administration, 2015. [Online]. Available: https://www.eia.gov/. [Accessed: 22-Oct-2018].

[2] J. Besant-Jones, "Reforming power markets in developing countries: what have we learned?," 2006.

[3] F. T. Sparrow, B. H. Bowen, and Yu Zuwei, "The Future of SAPP, WAPP, CAPP, and EAPP - With Inga," in IEEE PES GM 2005 Panel Session, 2005.

[4] IEA, "International Energy Agency, Africa Energy Outlook - a focus on energy prospects in sub-saharan africa," 2014. [Online]. Available: www.iea.org. [Accessed: 22-Oct-2018]. 
[5] "The World Bank," 2000. [Online]. Available: http://documents.worldbank.org/curated/en/371191468105872 879/pdf/30320.pdf. [Accessed: 22-Oct-2018].

[6] J. Ikeme and O. J. Ebohon, "Nigeria's electric power sector reform: What should form the key objectives?," Energy Policy, vol. 33, no. 9. pp. 1213-1221, 2005.

[7] P. O. Pineau, "Electricity sector integration in West Africa," Energy Policy, vol. 36, no. 1, pp. 210-223, 2008.

[8] J. Besant-Jones, "Reforming Power Markets in Developing Countries: What Have We Learned?," pp. 1-164, 2006.

[9] A. M. Foley, B. P. Ó Gallachóir, J. Hur, R. Baldick, and E. J. McKeogh, "A strategic review of electricity systems models," Energy, vol. 35, no. 12, pp. 4522-4530, 2010.

[10] C. Cramer and J. Tschirhart, "Power Pooling - an Exercise in Industrial Coordination," Land Econ., vol. 59, no. 1, pp. 24 34, 1983.

[11] ECOWAS, "West african power pool." [Online]. Available: http://www.ecowapp.org/en/documentation. [Accessed: 23Oct-2018].

[12] O. Adeoye and C. Spataru, "Sustainable development of the
West African Power Pool: Increasing solar energy integration and regional electricity trade," Energy Sustain. Dev., vol. 45, pp. 124-134, Aug. 2018.

[13] NEPAD, "New Partnership for Africa's Development: Action Plan for the Environmnet Initiative," 2003.

[14] COMMISSION OF THE EUROPEAN COMMUNITIES, "Interconnecting Africa: the EU-Africa Partnership on Infrastructure," 2006.

[15] WEC, "Regional Energy Integration In Africa," 2005.

[16] M. O. Oseni and M. G. Pollitt, "The promotion of regional integration of electricity markets: Lessons for developing countryies,” Energy Policy, vol. 88, pp. 628-638, 2016.

[17] P. O. Pineau, "Electricity sector integration in West Africa," Energy Policy, vol. 36, no. 1, pp. 210-223, 2008.

[18] World Bank, "Burkina Faso Power Sector Development Project," 2004.

[19] R. W. Bacon and J. Besant-Jones, "Global Electric Power Reform, Privatization, and Liberalization of the Electric Power Industry in Developing Countries1," Annu. Rev. Energy Environ., vol. 26, no. 1, pp. 331-359, 2001. 